\title{
POLÍTICAS NO FEMININO: TRANSFORMAÇÕES E SUBVERSÕES NÃO CENTRADAS NO ESTADO ${ }^{1}$
}

\author{
RAQUEL GUTIÉRREZ AGUILAR
}

\section{Apresentação}

\section{Flávia Almeida Pita \\ Hugo Belarmino de Morais \\ Laurenio Leite Sombra}

O pensamento da filósofa, matemática e socióloga mexicana Raquel Gutiérrez Aguilar ainda é pouco conhecido no Brasil. Até onde foi possível aferir, este é o seu primeiro texto publicado por aqui, em português.

A iniciativa de traduzi-lo partiu de Laurenio Sombra, ao inclui-lo na bibliografia do componente curricular "Filosofia Latino-americana", por ele proposto em 2018 para integrar o plano de curso da disciplina "Filosofia da América Latina", do curso de graduação em Filosofia da Universidade Estadual de Feira de Santana-UEFS, já que a língua espanhola era uma barreira para os graduandos. Mas a própria disciplina foi resultado, na verdade, das leituras e discussões desenvolvidas em grupo de professores/as e estudantes da UEFS (entre os quais Laurenio Sombra e Flávia Pita) integrantes do projeto de pesquisa $A$ constituição do sentido e dos sujeitos: uma investigação hermenêutica e política. Iniciado em 2015, o projeto envolve encontros presenciais para leitura coletiva e discussão, e no encadeamento de textos e autores, chegamos ao livro Horizontes Comunitario-populares: producción de lo común más allá de las políticas estado-céntricas $(2017)^{2}$, do qual faz parte o capítulo que pode ser lido a seguir.

No Projeto, como resultado da proposta de aprofundar a rede conceitual que envolve os "processos e estruturas fundamentais que embasam a constituição humana de sentido [...] e a constituição correlata de sujeitos individuais e coletivos", os pesquisadores foram se aproximando mais e mais de reflexões sobre os modos antagônicos e diferenciados de apreensão de sentido a partir dos quais são formuladas relações diferenciais e valoradas entre

\footnotetext{
${ }^{1}$ Tradução de Óscar Martinez, revisão de Flávia Almeida Pita, Hugo Belarmino de Morais e Laurenio Sombra. ${ }^{2} \mathrm{O}$ projeto está finalizando agora, e é sucedido por um novo, aprovado nas instâncias formais da UEFS em março de 2019: Nenhuma rede é maior do que o mar: rede de sentidos, antagonismo e ontologia. Neste, fica ainda mais explícito entre os objetivos "aprofundar a investigação sobre a peculiaridade da constituição de sentido latinoamericana em uma ideia de modernidade-colonialidade, a partir do pensamento descolonial”.
} 
homens e mulheres, pobres e ricos, negros e brancos, "ocidentais" e "não-ocidentais" 3 e tantos outros duplos que marcam o mapa das "rede de sentidos" em que nos inserimos e que são construídos no desenrolar do antagônico processo material-histórico. As leituras do grupo nos empurraram, especialmente, em direção às questões em torno da centralidade que assumiu o processo colonizatório para a realidade latino-americana. Assim, a importância de um movimento de descolonização de nosso pensamento - e da filosofia, em especial - nos conduziu a autores como Aníbal Quijano, Raúl Fornet-Betancourt, Enrique Dussel, Santiago CastroGoméz, John Holloway e, finalmente, Raquel Gutiérrez Aguilar ${ }^{4}$.

O chamado para a leitura da filósofa mexicana também chegava a nossos ouvidos por outros caminhos. Hugo Belarmino descobriu-a através do grupo de estudos formado no âmbito do Departamento de Geografia da Universidade Federal Fluminense, com a coordenação do geógrafo Carlos Walter Porto Gonçalves. Hugo e Flávia são colegas no doutorado (em andamento) do Programa de Pós-Graduação em Sociologia e Direito da Universidade Federal Fluminense (PPGSD-UFF). Assim, os bons ventos levaram notícias da força do pensamento de Raquel Gutiérrez, simultaneamente, à Bahia e ao Rio de Janeiro, e a coincidência das referências teóricas dos grupos reforçou para os colegas a certeza de que ali se apresentava algo que devia ser explorado.

Finalmente, a partir de tais leituras, entre 2018 e 2019, Hugo segue para o México, onde realiza estágio-sanduíche do seu doutorado junto ao Instituto de Ciencias Sociales y Humanidades da Benemérita Universidad Autónoma de Puebla - BUAP -, onde Raquel Gutiérrez Aguilar, ao lado de Mina Navarro e Lucia Insalata, conformam o seminário de investigación permanente Entramados Comunitarios y Formas de lo Político. Além dele, a Profa. Ana Maria Motta Ribeiro, professora da PPGSD-UFF, orientadora de Hugo e coorientadora de Flávia (e que conheceu o trabalho da filosofia mexicana através de seus orientandos), seguiu para um período de troca acadêmica com o grupo de investigadoras da BUAP. $^{5}$

\footnotetext{
${ }^{3}$ As aspas servem para lembrar que o termo não guarda correspondência exata com a localização geográfica. Laurenio Sombra pontua que, "mais do que uma definição teórica, a ideia de Ocidente (e seu oposto) pressupõe diversas e frequentemente tensas práticas de relações humanas" (2017, p. 196). Assim, se não se questiona a "ocidentalidade" dos Estados Unidos da América, o mesmo não acontece quando se fala da América Latina, que considerando a "ambiguidade de sua formação entre 'oligarquias brancas' e 'povos mestiços', acaba sendo conduzida a uma "espécie de entreposto entre mundo ocidental e não ocidental" (idem, ibidem).

${ }^{4}$ Destas investidas resultou o Dossiê "Dis-pensando o ocidente", organizado por Laurenio Sombra e Flávia Pita, e publicado na Revista Ideação (v. 1, n. 25, 2017), ligada ao curso de Filosofia da UEFS (disponível on line em $<$ http://periodicos.uefs.br/index.php/revistaideacao/issue/view/88>).

${ }^{5}$ Em fevereiro de 2019, de modo a marcar a conclusão dos trabalhos da dupla no Entramados, foi realizado o "Conversatório Internacional Brasil-México (UFF-BUAP): por uma sociologia desde abajo: el papel de la metodologia de campo em la investigación sobre formas no capitalistas de reproducción de la vida" (que também
} 
O mapeamento do trajeto e das coincidências que trouxeram o pensamento de Raquel Gutiérrez até esta tradução faz-nos pensar no quanto a colonialidade do poder (QUIJANO, 1992) ainda conforma nosso modo de produzir conhecimento, explicando a marginalidade do pensamento latino-americano no referencial teórico brasileiro. Faz lembrar o injustificável muro ainda de pé entre a América Latina hispânica e o Brasil. E comprova a potência sedutora do que Raquel Gutiérrez e o Entramados Comunitarios vêm produzindo, explicando o esforço coletivo em torno desta publicação e sua apresentação para as/os brasileiras/os interessadas/os em deslocar os desgastados eixos do conhecimento que se produz, tanto academicamente quanto no acontecer das lutas populares, em direção à América latina, ao popular, ao comum e ao feminino.

A força do pensamento de Raquel Gutiérrez Aguilar parece ser nutrida por uma biografia peculiar. Nascida no México, ela se licenciou em Matemática na Universidad Nacional Autónoma do México nos anos 1980. Em 1984, juntamente com seu então companheiro Álvaro Garcia Linera, seguiu para a Bolívia, onde se envolveram nas lutas das comunidades aymarás e quéchua, participando da fundação do Ejército Guerrillero Tupac Katari (EGTK), atividades que os levaram à prisão por cinco anos, acusados de terrorismo. Em 1998, foi cofundadora em La Paz do grupo Comuna, ao lado de Luis Tapia, Raúl Prada e García Linera, entre outros. Nos anos 2000, participou ativamente do que ficou conhecido como a Guerra da Água de Cochabamba, marco das lutas comunitário-populares na América Latina, quando os cochabambinos reverteram a privatização do serviço local de fornecimento de água.

A sua participação nas lutas populares bolivianas inspirou sua tese de doutorado, da qual resultou o seu livro mais conhecido, Los Ritmos del Pachakuti, ainda sem tradução em português.

Raquel Gutiérrez vive no México desde 2001. Hoje é professora do Instituto de Ciencias Sociales y Humanidades da Benemérita Universidad Autónoma de Puebla - BUAP -, onde coordena o seminário de investigación permanente Entramados Comunitarios y Formas de lo Politico.

O texto "Políticas no feminino: transformações e subversões não centradas no Estado" faz parte do livro Horizontes Comunitario-populares: producción de lo común más allá de las políticas estado-céntricas, que reúne textos datados entre 2011 a 2015 e foi publicado pela primeira vez em 2016, no México. Para esta tradução, utilizamos a edição madrilenha da

contou com a participação de Flávia Pita). Está sendo organizado um dossiê com trabalhos produzidos a partir deste encontro, a ser publicado na Revista Confluências, vinculada ao PPGSD-UFF. 
Traficante de Sueños, de 2017. Nela, a própria Autora inaugura o texto fazendo a seguinte afirmação:

Este trabalho é parte de uma reflexão muito mais ampla desenvolvida no âmbito do seminário de investigação permanente "Entramados comunitários y formas de lo político" da Pós-Graduação em Sociologia do ICSyH-BUAP. Uma versão anterior deste documento foi publicada em Escárzaga, Gutiérrez, et al (coord.), Movimiento indígena en América Latina: tierra-territorio, autonomía, estado y transformación social, vol. III, Puebla, ICSYH-BUAP, 2014.

Raquel Gutiérrez Aguilar filia-se, em suas próprias palavras, “à tradição do marxismo crítico ou aberto", apontando como suas influências diretas Adorno, Bloch, Horkheimer, Benjamim (2017, p. 21). Os pressupostos da dialética negativa adorniana são perceptíveis em seus esforços por uma filosofia da não identidade, produzida a partir da práxis histórica, mas há uma ênfase, para além dos autores citados, às lutas "desde abajo", aos modos de reprodução da vida cultivados pelos povos originários da América Latina, à sua resistência contra o silenciamento imposto de fora, por suas formas de pensar e praticar a política a partir do comum.

Em Políticas en femenino: transformaciones y subversiones no centradas en el estado, Raquel Gutiérrez nos apresenta várias dessas ideias, refletindo especialmente sobre três peças da "constelação conceitual" em torno do que denominou de "política no feminino": o comum, as lógicas de sua produção e o modo peculiar que nele se dá a relação Estado-sociedade.

A tradução do texto foi realizada por Óscar Martínez, a quem congratulamos pela qualidade do trabalho, e revisada pelos/as que assinam esta apresentação. As revisões tiveram um caráter interpretativo em função das pesquisas dos revisores, portanto não diziam respeito à qualidade da tradução. As notas dos/as revisores/as são precedidas da sigla "N.R.".

Boa leitura!

\section{Referências:}

AGUILAR, Raquel Gutiérrez. Horizontes Comunitario-populares: producción de lo común más allá de las políticas estado-céntricas. Madrid: Traficante de Sueños, 2017.

QUIJANO, Aníbal. Colonialidad y Modernidad-Racionalidad. In: BONILLA, Heraclio (Org.). Los conquistados: 1492 y la población indígena da las Américas. Santafé de Bogotá, Colombia: Tercer Mundo; Ecuador: FLACSO: Libri Mundi, 1992

SOMBRA, Laurenio Leite. O Ocidente como problema filosófico". Revista Ideação, n. 35, jan./jun. 2017, pp. 193-242. 


\section{POLÍTICAS NO FEMININO: TRANSFORMAÇOES E SUBVERSÕES NÃO CENTRADAS ${ }^{6}$ NO ESTADO RAQUEL GUTIÉRREZ AGUILAR}

Neste trabalho apresentarei, de forma sintetizada, algumas reflexões gerais sobre as tensões entre o que eu chamei de "horizonte comunitário-popular" e as variadas perspectivas políticas dos Estados plurinacionais em construção. Entendo por "horizonte comunitáriopopular" um amplo - porém às vezes difícil de ser expressado - conjunto de esperanças e práticas de transformação e subversão das relações de dominação e exploração, como o que tem se tornado visível e audível nos Andes e na Mesoamérica, de maneiras diferentes, desde o amanhecer $^{7}$ de 1994 e durante as lutas mais intensas da primeira década do século XXI. Essas lutas têm sido protagonizadas, principalmente, pelos diversos povos e movimentos indígenas de nossos países, percorrendo diversos caminhos e alcançando um maior ou menor sucesso em suas aspirações.

No entanto, vale a pena notar, também, as características nitidamente populares ou, melhor, comunitário-populares que adquiriram, ao longo dessa mesma época, certas lutas realizadas nas cidades, impulsionadas e sustentadas por homens e mulheres assentados no que são geralmente chamadas de "periferias urbanas" ${ }^{8}$. De acordo com o olhar aqui sustentado, o horizonte comunitário-popular é expressado, em formas múltiplas e particulares, através do que pode ser chamado de lógicas heterogêneas e multiformes de produção e atualização do comum ${ }^{9}$. De forma geral, tais lógicas do comum, em tempos quotidianos e ordinários, se desdobram partindo de fins centralizados na conservação e cuidado dos recursos materiais coletivamente

\footnotetext{
${ }^{6}$ N.R.: Optamos por centradas, no lugar de centralizadas, ao traduzir "no centradas em el estado". "Estadocêntrico" é o olhar que leva sempre em consideração a relação com o Estado ou a prevalência do Estado. Quando Raquel Gutiérrez propõe uma política "não centrada no Estado" ela parece apontar para "um outro olhar", outra mirada. O termo "centrado" nos pareceu corresponder melhor a esta ideia do que "centralizado": na prática, é possível fazer uma análise não centralizada no Estado (mas nas suas relações, ambiguidades etc.) e mesmo assim colocar o Estado como lugar privilegiado da política, o que parece ser o interesse da autora.

${ }^{7}$ N.R.: Mantemos a tradução literal do "amanecer" presente do texto original pois cremos que a Autora refere-se ao "despertar zapatista", símbolo do "amanhecer de um novo ciclo, de um outro mundo possível. Em primeiro de janeiro de 1994, no estado mexicano de Chiapas, o Exército Zapatista de Libertação Nacional tomou San Cristóbal de das Casas e várias outras cidades, inaugurando uma experiência de autonomia política e comunal que permanece viva até o presente.

${ }^{8}$ Para uma reflexão mais pormenorizada sobre as tensões entre os horizontes comunitário-popular e nacionalpopular a partir do desenvolvimento das mobilizações e revoltas na Bolívia entre 2000 e 2005, pode ser revisto R. Gutiérrez, Los ritmos del Pachakuti, México DF, ICSyH-BUAP-Bajo tierra ediciones, 2009.

${ }^{9}$ Lucía Linsalata é quem trabalhou mais detalhadamente o seguimento e a compreensão de tais lógicas polimorfas quotidianas de produção do comum. Em particular, veja-se Linsalata, Cuando manda la Asamblea. Lo comunitário-popular en Bolivia: una aproximación desde los sistemas comunitarios de agua de Cochabamba, tese de doutorado em Estudos Latino-Americanos, México DF, UNAM, 2014.
} 
disponíveis, colocando como seu eixo central a garantia das condições materiais para a reprodução da vida coletiva.

Por esta razão, esse tipo de práticas produtivas e políticas amplamente difundidas e, no entanto, às vezes dificilmente perceptíveis, comprometidas com a reprodução quotidiana da vida material, tende a demonstrar um caráter conservador e defensivo que privilegia a autoproteção coletiva. No entanto, tais lógicas do comum mostraram seu poder expansivo, a sua capacidade transformadora, e fins muito mais amplos foram propostos durante o Awqa Pacha ${ }^{10}$, ou seja, no tempo extraordinário das lutas mais enérgicas e generalizadas ocorridas nos últimos anos. De acordo com essa visão, agora nós vivemos tempos que exigem uma reflexão profunda e crítica sobre aquilo que foi alcançado, para desta forma compreender com maior clareza quais são seus limites e possibilidades.

Assim, não é objetivo deste texto fazer nenhum balanço das dificuldades que enfrentam os chamados Estados plurinacionais em construção para realmente se tornarem o que se propõem. Em vez disso, a intenção é apresentar de modo esquemático uma proposta de intelecção de outros horizontes de transformação que têm encorajado as lutas que pariram tais Estados plurinacionais, entendendo-as, basicamente, como esforços politicamente autônomos, muitas vezes ambíguos e contraditórios, de defesa, produção, atualização e expansão do comum.

$\mathrm{Na}$ maior parte dos casos, tais esforços propuseram, explicitamente, em primeiro lugar, limitar, enganar e confrontar o predomínio mercantil-corporativo sobre amplas paisagens da geografia social. Em segundo lugar, e geralmente de forma implícita, as diversas ações de levantamento e mobilização conseguiram subverter, perturbar e reorganizar de forma direcionada a relação sociedade-governo nos diferentes países onde houve lutas generalizadas: ao se mobilizarem repetidas vezes para repudiar alguma medida governamental particularmente odiosa, os contingentes mobilizados, de natureza heterogênea, foram gradativamente colocando em situação de crise os sistemas democráticos procedimentais que afiançam e garantem ao sistema de partidos o monopólio da tomada de decisões públicas, fato que exclui a maioria social e, acima de tudo, os povos indígenas.

${ }^{10}$ N.R.: É em Los Ritmos del Pachakuti: levantamento y movilización em Bolivia (2000-2005) (México, D.F.: Sísifo ediciones, Bajo Tierra Ediciones y el Instituto de Ciencias Sociales Y Humanidades "Alfonso Vélez Pliego" de la BUAP, 2009) que Raquel Gutiérrez narra, discute e interpreta esses "tempos extraordinários" na Bolívia, propondo uma metodologia para analisar o "alcance práctico de las luchas" e seu "horizonte interior" (AGUILAR, 2009, p. 361). 
Essas formas do político, com frequência desdobradas do que já foi chamado de "âmbito social-natural" $^{11}$ - e, mais recentemente, de "política das necessidades vitais"12 -, antagonicamente contrapostas à quase sempre violenta apropriação privada dos bens comuns e que, em sua implantação, modificam de maneira drástica as mais fundamentais relações de comando-obediência que segmentam, hierarquizam e estruturam as sociedades -, é isso que eu chamo de política no feminino.

O qualificativo "no feminino", cuja intenção é distinguir uma forma específica do político, procura enfatizar duas questões. Em primeiro lugar, a de estabelecer que o eixo de atenção e o ponto de partida dessa forma do político é o compromisso coletivo com a reprodução da vida em seu conjunto, a humana e a não-humana. ${ }^{13}$ Seguindo a perspectiva analítica de Silvia Federici (2013), que aponta como uma das mais graves consequências do avanço e predominância históricos do capitalismo em todo o mundo a divisão brutal da vida humana em dois âmbitos segmentados e excludentes: o da produção - de mercadorias, isto é, de capital - e o da reprodução da vida em seu conjunto - inclusa a procriação - ; eu recolho o desafio da autora ao convocar-nos para pensar sobre as possibilidades de transformação social - assuntos políticos por excelência - do ponto de vista da reprodução da vida material, e não de qualquer uma das variadas formas de gestão da acumulação do capital. Em segundo lugar, eu uso a expressão "política no feminino" porque, ao tomar como ponto de partida e eixo do político aquilo que está relacionado com a produção, a defesa e ampliação das condições para

\footnotetext{
${ }^{11}$ Hegel, em sua Filosofia do Direito, propõe a existência de três âmbitos da vida moderna que são objeto do direito: o civil, o político e o "social-natural". No primeiro se estabelecem as normas que regem tanto a propriedade quanto os intercâmbios mercantis, isto é, é o âmbito plenamente capitalista da vida moderna; o segundo, isto é, o político, abrange o que é relativo às formas de participação de cada indivíduo que merece ser cidadão nas decisões gerais; sobre o ambiente social-natural, que é o território onde a vida é reproduzida ou, mais precisamente, onde tende-se a reproduzir a força de trabalho como uma mercadoria, o filósofo não faz nenhuma reflexão além de estabelecer as condições de pertencimento de cada elemento desse âmbito à esfera do público-estatal. E é justamente a partir desse território, não totalmente subordinado às relações capitalistas ou à normativa estatal, e que em muitos dos nossos países ultrapassam o território "dos lares" considerados individualmente para formar tecidos variados e heterogêneos com propósitos comuns, é desde ele que, segundo o meu ponto de vista, germinam e se alimentam as lutas sociais mais enérgicas, as quais desestabilizam a ordem estatal-capitalista e propõem a reconstrução da vida política em novas condições.

12 Vide R. Gutiérrez et al, 2000.

${ }^{13}$ Mina Navarro enfatiza que a defesa e produção do comum geralmente inclui a questão da manutenção da vida humana e não-humana em tempos de "expropriações múltiplas" pelo capital e dos diferentes Estados nacionais; vide Luchas por lo común. Antagonismo social contra el renovado cercamiento y despojo capitalista de los bienes naturales en México, tese de doutorado em Sociologia, México, ICSyH-BUAP, 2012. [N.R.: A expressão original é "despojos múltiples". O conceito formulado por Navarro realiza uma ampla revisão - e ampliação - do debate sobre a "acumulação primitiva" e os "cercamentos" na tradição marxista a partir de uma dupla operação dentro da ecologia política: por um lado, a autora defende o caráter contínuo/permanente das violências e expropriações perpetradas pelo capital para além da extração de mais-valor na relação clássica capital/trabalho; por outro, aponta como essas expropriações e violências engendram diversos processos de separação funcionais à acumulação ampliada de capital, não só dos produtores e seus meios de existência, mas entre as esferas econômica e política, entre o humano e a natureza, o trabalho produtivo e o reprodutivo, entre mente e corpo etc.
} 
a reprodução da vida em seu conjunto, é imediatamente necessário estabelecer algum tipo de sentido de inclusão, o qual é dificilmente analisável da perspectiva dos cânones clássicos de compreensão do político, predominantemente masculinos e ligados à acumulação do capital, além de sedimentados na consagração de padrões de pertencimento, ou seja, de definições que estabelecem exclusões e separações. Algumas autoras chamam essas formas do político de formas comunitárias ou, inclusive, de políticas indígenas ${ }^{14}$. Eu escolho nomeá-las de "políticas no feminino" porque seu eixo e coração são a reprodução da vida material, foco de atenção tradicional da atividade feminina ${ }^{15}$, não exclusiva, porém crucial, e porque sua qualidade expansiva e subversiva é fortalecida com as possibilidades que ela oferece de incluir e articular a criatividade e a atividade humanas para fins autônomos.

Claramente, a política no feminino, na medida em que é uma política sem a ambição de gerir a acumulação do capital, mas que procura limitá-la reiteradamente, é uma política não estadocêntrica. Isto é, o confronto com o Estado não é proposto como sua questão central, nem se focaliza na construção de estratégias para sua "ocupação" ou "tomada"; ela, basicamente, fortalece-se na defesa do comum, desloca a capacidade de comando e de imposição do capital e do Estado e pluraliza e amplifica múltiplas capacidades sociais de intervenção e decisão em assuntos públicos: dispersa o poder ao permitir a reapropriação da palavra e da decisão coletiva sobre os assuntos que são competência de todos, porque a todos afetam.

Os eixos dessa forma do político são normalmente o cuidado e a preservação, bem como a reapropriação social da riqueza e dos bens produzidos coletivamente, que garantem a possibilidade de reproduzir a vida coletiva. Então, esse conteúdo, em lugar de apontar para um modelo de governo, aponta para um caminho de vida e de luta, e enfrenta imensas dificuldades de se expressar, através de pensamentos abertos e flexíveis, em meio à enorme acumulação existente de noções e sensos comuns - centrados no predomínio do capital, do Estado, do comando e do masculino - sobre o político que vai se tornando cada vez mais rígido e impotente ${ }^{16}$.

\footnotetext{
${ }^{14}$ Gladys Tzul, por exemplo, investiga as políticas indígenas que foram implantadas ao longo da história pelos sistemas de governo comunitário-indígena da região de Totonicapán, na Guatemala. Tese de Doutorado em preparação para a Pós-Graduação em Sociologia, ICSyH-BUAP. [N.R.: Gladys Tzul já defendeu a Tese de Doutorado e publicou o resultado de sua investigação (TZUL, Gladys. Sistemas de gobierno comunal indígena: mujeres y tramas de parentesco. Guatemala: Ediciones Sociedad Comunitaria de Estudios Estratégicos-TZ'I'KINMaya' Vuh. Chuimeq'ena', 2016)]

${ }^{15}$ Com a afirmação de que a atividade feminina tem sido tradicionalmente associada a tarefas centradas na reprodução da vida, não estou me comprometendo com nenhuma essencialidade que ligue as mulheres à reprodução, e sim simplesmente observando um fato histórico e procurando submeter à crítica o "horizonte fraudulento da igualdade" - jurídica, formal, abstrata - que o capital e a modernidade oferecem como limite à condição das mulheres e, cada vez mais, à dos homens jovens (vide Rivera Garretas, 2002).

${ }^{16}$ Sobre esse assunto, pode-se ver R. Gutiérrez, 2011.
} 
Sugiro então três noções ou ideias com as quais pretendo apresentar uma constelação conceitual ao redor do que eu chamo de política no feminino, entendendo-a como uma linguagem e não como um modelo. A assunção dessa forma do político como uma linguagem significa pensá-la como um conjunto articulado de desejos e anseios compartilhados, de compromissos e práticas coletivas que permitem a nós, homens e mulheres, expressarmos o que sentimos e pensamos, dando-nos a possibilidade de esperançar ${ }^{17}$, que é a condição necessária de nossa jornada, do nosso percurso político para além de modelos de governo e comandos que, em última instância, garantem e se comprometem com alguma forma de acumulação de capital - estatal, privado-nacional, transnacional, ou a combinação delas. Essas três noções em questão são: o comum, as lógicas de produção do comum e, uma vez que as duas anteriores são colocadas, a relação Estado-sociedade que esse tipo de pensamento propõe. Para levar à frente o propósito aqui declarado, meu trabalho é dividido em duas partes; na primeira eu desenvolvo alguns elementos sobre o comum e suas lógicas de produção e reprodução; na segunda, eu abordarei aspectos da relação Estado-sociedade que requerem um pensamento não estadocêntrico do político.

\section{Lógicas de produção do comum: o conteúdo da política no feminino}

Entendo como "lógica contemporânea de produção do comum" uma dinâmica associativa particular e específica, isto é, temporal, geográfica e historicamente situada, e que geralmente visa alcançar objetivos específicos quase sempre ligados a assegurar ou proteger as condições para a reprodução coletiva em meio a ameaças drásticas de expropriação ou agravo. Nesse sentido, as lógicas de produção do comum não aludem nem necessariamente nem unicamente apenas às antigas práticas comunitárias dos povos indígenas; elas são, em vez disso, práticas comunitárias cuja geração e conservação, embora enraizadas em tempos distantes e em enérgicas lutas de resistência e de criação da vida, também podem ser entendidas como uma reatualização prática contemporânea, fundada, no entanto, em antigos conjuntos de saberes coletivos internalizados - e reproduzidos - por aqueles que se associam em prol dos propósitos atuais.

\footnotetext{
${ }^{17}$ Marlon Santi, liderança amazônica do Equador, usa esse termo para expressar o que acontece nas deliberações e reuniões em que as comunidades projetam e organizam sua luta contra a invasão das corporações petrolíferas em seus territórios. Marlon Santi, depoimento apresentado nas III Jornadas Andino-Mesoamericanas Movimento indígena: tierra-territorio, autonomía, estado y transformación social, México DF, setembro de 2011.
} 
As lógicas de produção do comum, então, não são apenas dinâmicas associativas de luta e criação reatualizadas a partir de práticas indígenas, embora claramente sejam os diversos povos indígenas do continente, e em particular da Bolívia, Peru, Equador, Colômbia, México, Guatemala e Chile, quem melhor souberam preservar e adaptar as habilidades necessárias para sua produção.

Antes de analisar mais detalhadamente as dinâmicas associativas auto-organizativas que diagramam lógicas de produção do comum, será útil fazer algumas reflexões sobre o significado que eu atribuo ao termo "comum". A definição da palavra "comum", estabelecida no primeiro verbete do dicionário, é a seguinte: "É dito do que, não sendo privadamente de nenhum, pertence ou se estende a vários". Uma entrada posterior indica que "comum" se refere a "o baixo, de classe inferior, desprezível". Além disso, também explica o significado da expressão "em comum", aplicável a alguns verbos como ter, fazer etc., de tal forma que "ter em comum" duas ou mais pessoas ou coisas é explicado como "participar em uma mesma qualidade ou circunstância, ser semelhante $a$ ela".

A partir dessas noções, a constelação conceitual em torno do comum, que dará sentido ao uso que eu faço desse termo, relaciona e sintetiza parcialmente vários elementos: o comum é imediatamente contrário ao privado, entendido como aquilo de que se apropria algum em detrimento do que é possuído por vários. Aqui vale a pena destacar o fato de nós entendermos o comum não como aquilo que é "de nenhum e de todos", o que indica, antes, traços associados à compreensão contemporânea de "público". O comum, ao contrário, é o que é possuído - ou compartilhado - coletivamente por vários. E esses "vários" que compõem o grupo específico possuidor podem ser multiformes e extremamente heterogêneos, mas em qualquer caso eles têm em comum, enquanto co-participantes de uma qualidade ou circunstância, o fato de se encontrarem espacialmente e temporalmente situados. Ou seja, os homens e as mulheres que compartilham o comum compõem coletividades particulares e específicas que estabelecem, também, normas específicas para usufruírem dele e para transmitirem tais direitos às gerações subsequentes.

Mas existe uma nuance de diferenciação, não menos importante, no significado que atribuo ao comum, em contraste com a definição estabelecida no dicionário, e ela é a relação implicitamente estabelecida dessa noção com o conceito de propriedade. Eu considero que tal associação entre comum e propriedade - claramente construída pelo uso da palavra "pertencer" - oculta muito mais do que esclarece. Em contextos modernos, institui-se e normatiza-se a propriedade sobre as coisas, ou seja, são os objetos que podem estar sob uma relação de 
pertencimento - ou propriedade - com os sujeitos, que têm domínio sobre eles. Ou são os indivíduos que pertencem a associações instituídas e regulamentadas, sem que isso expresse uma relação de domínio daqueles por estas, ainda que estejam previstas obrigações e compromissos.

No entanto, em outros contextos, o comum pode não ser necessariamente pensado em tais cânones. É esse o nó da abertura conceitual na qual eu estou engajada: desligar a compreensão do comum do lastro da propriedade - especificamente, os significados de propriedade sob sua compreensão moderna, isto é, como propriedade privada, que são regulamentados nas leis civis, nos diversos e muito semelhantes códigos civis nacionais possibilita estar aberto a pensar o comum não apenas como algo dado e que é compartilhado, mas, acima de tudo, como algo que está sendo produzido, reproduzido e reatualizado de maneira contínua e constante.

O comum, sob essa perspectiva, deixa de ser um objeto ou coisa sob o domínio de alguns para ser entendido como ação coletiva de produção, apropriação e reapropriação do que há e do que é feito, do que existe e do que é criado, do que é oferecido e gerado pela própria Pachamama e, também, do que a partir disso foi produzido, construído e alcançado pela articulação e esforço comum de homens e mulheres situados historicamente e geograficamente. Daí a pertinência da pesquisa sobre a produção do comum, suas lógicas associativas e suas dinâmicas internas, como questão fundamental e cujos horizontes políticos não estão focados no que é estatal - portanto, público e universal.

Uma vez traçadas as características anteriores, as quais eu associo ao significado de comum, vou apresentar algumas ideias gerais ao redor da lógica de sua produção, produto de vários estudos sobre práticas comunitárias quotidianas e locais que, seja para resolver problemas específicos ou necessidades urgentes, são implementadas, reatualizadas, adaptadas e recriadas, diversas vezes, pelas contribuições [acuerpamientos] - antigas e modernas - de homens e mulheres. A aposta teórica que dá orientação a esse exercício de formalização tem um duplo objetivo: em primeiro lugar, o de apresentar um quadro lógico e, portanto, com ambição generalizante, que descreva a dinâmica de produção do comum para desligá-lo das ideias de particularismo, exotismo ou anacronismo associadas a tais dinâmicas de produção, reprodução e luta. Em segundo lugar, o de levantar questões sobre a possibilidade de generalização e articulação, além do local, de tais lógicas quotidianas, a possibilidade de serem pensadas como essencialmente políticas e serem entendidas como fundamento possível de projetos políticos plurais que, por um lado, transfiram, deformem, subvertam e reorganizem o 
horizonte limitado do progressismo extrativista - o qual procura se colocar como limiar drástico para potenciais transformações políticas, possíveis tanto na Bolívia quanto em outros países do continente americano - e, pelo outro, disputem o restrito significado político que está sendo atribuído ao conceito de Estado plurinacional.

\section{Lógicas de produção do comum: a experiência de Cochabamba}

Uma experiência insuperável para entender a ductilidade das lógicas de produção do comum é a experiência dos sistemas comunitários de água potável em Cochabamba ${ }^{18}$. Tais sistemas se compõem de acordos locais de vizinhos auto-organizados no bairro ou na vila para resolverem coletivamente o problema do acesso à água potável, após a onda de migração para a cidade ocorrida como resultado da ofensiva neoliberal de 1985. Os comitês de água potável, sistemas de água potável e saneamento, projetos de água, etc., termos, todos eles, que distinguem as diferentes experiências locais, surgiram nos anos noventa e foram-se generalizando durante a última década ${ }^{19}$. Eles são constituídos, em todos os casos, por uma articulação de várias unidades domésticas de assentamentos recentes que têm a necessidade e o propósito de se abastecer coletivamente com água em suas casas, serviço público ausente nesses locais. Vale destacar que as famílias organizadas nesses sistemas hídricos ficaram muito tempo sem exigir ao município o fornecimento desse serviço básico, já que tiveram a experiência de não receber nada - ou quase nada - das instituições públicas. No caso do acesso à água potável, uma necessidade que teoricamente deveria ser atendida pelo Serviço Municipal de Água Potável (SEMAPA), o desconhecimento e o desdém por parte das autoridades municipais em relação às necessidades das novas famílias assentadas nas áreas periféricas da cidade de Cochabamba eram habituais. Por isso, após começar a viver em terrenos carentes de praticamente tudo, os novos vizinhos se propuseram a equipar essas áreas com acesso à água, criando numerosas associações de sistemas independentes de água potável.

\footnotetext{
18 A autora teve a oportunidade de participar diretamente da Guerra del Agua, conhecendo intimamente sua instância organizacional mais visível: a Coordinadora del Agua y de la Vida. Posteriormente, participou do Comité Técnico de Apoyo à "desprivatização" do SEMAPA. A informação atualizada sobre os Sistemas de Agua Potable de Cochabamba, em grande parte, vem do segundo capítulo da tese de doutorado de Lucía Linsalata, cit., 2014.

${ }^{19}$ Atualmente, em toda a Villa Sebastián Pagador - uma grande área da Zona Sul de Cochabamba - operam seis sistemas comunitários de água atendendo 1.600 famílias. A APAAS (Associação de Produção e Gestão de Água e Saneamento) é a mais antiga organização, fundada em 1991. Ela foi seguida pelo PDA Villa Sebastián Pagador (Projeto de Desenvolvimento de Área) em 1996, o CODAPO (Comitê de Água Potável) em 2004, o CODALPA (Comitê de Água Alto Pagador), a ACOSBAPA (Associação Comunitária de Serviços Básicos de Água Potável e Esgoto) em 2005, e o Comitê de Água 22 de Abril em 2006. Dados de Lucia Linsalata, 2014, Capítulo II.
} 
O que tem relevância aqui é que tais sistemas de água foram constituídos sob uma lógica associativa que podemos nomear claramente de lógica de produção do comum. Numa apresentação esquemática, a dinâmica de auto-organização dos sistemas comunitários e independentes de água potável tem sido a seguinte:

i) Estabelecer uma assembleia para definir quem irá cooperar para alcançar determinado fim. A assembleia, de forma geral, é composta por um membro de cada uma das unidades domésticas estabelecidas em um bairro; e, nesse sentido, re-produz e re-elabora a ancestral técnica andina de organização para articular segmentos autônomos que se associam visando finalidades específicas.

ii) Deliberar até esclarecer coletivamente o propósito de sua associação, e fazer acordos sobre como pode-se alcançar esse objetivo; desta forma, a deliberação dos objetivos e os acordos resultantes sobre as maneiras de proceder são particulares e locais. Até certo ponto, mediante a deliberação, os participantes nas assembleias se propõem e conseguem, basicamente, "dar uma nova forma ao que existe".

Estabelecer a obrigação de participar tanto na assembleia quanto nas tarefas necessárias para alcançar o objetivo acordado; isso gera o direito de usufruto daquilo que é construído. Simultaneamente, é estabelecida uma autoridade - ou um responsável - cuja tarefa é coordenar ou viabilizar os acordos de todos, estabelecendo limites claros para suas prerrogativas: tem autoridade apenas para coordenar os acordos alcançados. É desta forma que é limitado o mecanismo de delegação da soberania que sustenta as práticas políticas de signo liberal.

Vale a pena notar que o sistema dinâmico de articulação política para propósitos específicos assim estabelecidos não é nem fechado nem totalmente aberto, poderíamos descrevê-lo como "poroso": ele admite e busca apoios do exterior e, frequentemente, os assimila à sua lógica; além disso, é criativo: produz novidades e resolve problemas. O agrupamento tem possibilidades de crescimento por meio da inclusão de novos associados, embora haja claramente um limite para esse crescimento. De forma geral, após um certo grau que, de acordo com a decisão coletiva, ultrapassa os limites do que é apropriado, tende-se a criar um novo segmento semelhante ao primeiro, que segue a mesma lógica e discute os termos da possível articulação-cooperação entre eles.

Essa experiência particular exibe traços básicos importantes - e comuns, vale a redundância - das lógicas de produção do comum, que podem ser distinguidos em muitas outras experiências e nas quais elas são apresentadas de maneira semelhante, porém distinta, em sua especificidade concreta. Tais características são: a conformação de uma assembleia, o uso 
sistemático da palavra para a deliberação coletiva dos objetivos que pretendem ser alcançados, a delimitação de um perímetro que distingue aqueles que são incluídos no sistema ou rede participando da assembleia e contribuindo para a produção da decisão comum - e, finalmente, a instituição de conjuntos normatizados de obrigações e compromissos com aquilo que está sendo produzido de forma comum, a partir de cujo cumprimento obtêm-se os direitos de usufruto assim como as garantias de posse.

Essa dinâmica de produção do comum consegue adquirir, especialmente em momentos de agressão, uma grande vitalidade expansiva. Essa força é nutrida pela coesão e pela capacidade de ação geradas a partir de si mesma; isto é, a vitalidade energética que apoios [acuerpamientos] construídos a partir das lógicas de produção do comum conseguem desenvolver em momentos de agressão é baseada na capacidade deliberativa alcançada e na possibilidade de estabelecer novos fins e objetivos; assim, nesses casos, simultaneamente a rede protege e defende aquilo que é produzido em comunidade dos ataques externos que impulsionam a privatização ou a apropriação privada do que foi construído e conservado por meio do trabalho comum; ao mesmo tempo, ela desestrutura e destotaliza antigas relações de poder e comando que governam a vida política local ou regional, ou de maior escala. A política implantada a partir daí, dessas múltiplas e variadas áreas de associação para a satisfação das necessidades vitais, a política baseada em lógicas de produção do comum, é uma forma legítima da política que pode ser chamada, para distingui-la de outras formas políticas, de política no feminino.

No entanto, as ações realizadas por grupos heterogêneos de homens e mulheres que defendem o comum - pois eles sabem que foram eles mesmos que o produziram - com frequência são criticadas e desvalorizadas como simples explosões tumultuosas de aborrecimento e, quando são muito radicais, insiste-se sempre na ideia de que elas têm um caráter "pré-político" e apenas defensivo. É costume estabelecer, ainda, que essa forma política deve obrigatoriamente dar lugar, ater-se e conformar-se aos modos canônicos da política moderna, delegativos, fortemente hierarquizados e tendenciosamente monopolizadores da decisão coletiva sobre questões comuns. A possível qualidade expansiva da política de produção do comum e a tensão sistemática que ela estabelece com o comando político instituído - ancorado em outras lógicas - é o que abordarei na segunda parte deste trabalho. Vale salientar por enquanto que, de acordo com essa visão, essa contradição tem sido a tensão política mais significativa na Bolívia e parcialmente no Equador, países onde estão sendo construídos Estados plurinacionais. 


\section{Estados plurinacionais e esforços heterogêneos de produção-defesa-reprodução do comum}

Nesta segunda parte, revisarei brevemente um caso onde são visíveis os contrastes e as tensões entre a lógica política estatal - mesmo se falarmos de uma tendência de Estado plurinacional - e vários esforços coletivos para a produção do comum; para isso, analisarei as lutas que os homens e as mulheres dos povos yuracaré, chimán e mojeño trinitario, habitantes do Territorio Indígena e do Parque Nacional Isiboro Sécure (TIPNIS), têm realizado em defesa de seu território contra a ameaça de construção de uma rodovia, na qual os interesses de expansionismo do capital brasileiro estão ligados aos de certos segmentos de produtores de folha de coca do Chapare e também do governo da Bolívia ${ }^{20}$.

Em geral, essa disputa tem sido analisada como manifestação de uma das contradições mais agudas que o atual governo do MAS [Movimento al Socialismo, partido hegemônico do governo Evo Morales, na Bolívia] enfrenta: entre seu compromisso com um modelo extrativista primário-exportador patrocinado principalmente por interesses brasileiros e transnacionais e sua disposição à construção de um Estado plurinacional baseado em outro tipo de modelo econômico (Paz, 2012: 8; Tapia, 2012). De minha parte, focar-me-ei no conflito entre as variadas lógicas de produção do comum exibidas pelos povos indígenas das Tierras Bajas e as dificuldades de, simultaneamente, focalizar em uma lógica estatal, mesmo que de tendência plurinacional.

Nesse sentido, segundo a perspectiva mantida aqui, o que vem acontecendo no TIPNIS pode ser enquadrado numa busca muito mais ampla dos povos indígenas da Bolívia para conquistar seus direitos e um domínio pleno sobre os territórios que habitam, mais além do fato de vários desses territórios terem efetivamente recebido, durante o governo de Morales, o título de "Territorios indígenas originarios campesinos" (TIOC) ${ }^{21}$.

Na minha opinião, a questão básica que até agora se expressa como um confronto agudo é a questão da democratização-dispersão das prerrogativas de decisão política sobre o território, secularmente monopolizadas pela instituição estatal ou pelos poderosos latifundiários locais.

\footnotetext{
${ }^{20}$ Uma explicação documentada e completa sobre a questão do TIPNIS pode ser encontrada em Sarela Paz, 2012. Para o presente trabalho, eu me nutri bastante com a informação precisa fornecida por essa autora, embora eu dialogue de forma crítica com o seu argumento, sugerindo que o que fazem e dizem homens e mulheres das cidades mencionadas é uma forma legítima de política que abre uma possibilidade diferente de articulação do político. A questão de se o arcabouço do Estado plurinacional boliviano poderia ser o mais adequado para cobrir tais práticas - embora não o seja atualmente - é uma discussão que eu não abordo nesses mesmos termos.

${ }^{21}$ Sobre a questão da política agrária na Bolívia nos últimos anos, incluindo a ampliação da titulação de terras no Oriente, pode ser visto Gutiérrez y Salazar, 2012. Especificamente sobre o TIPNIS, Sarela Paz nos informa que esse território foi reconhecido como "território indígena" em 1990 e intitulado como Terra Comunitária de Origem (TCO) em 1996 (Paz, 2012: 12).
} 
Aqui está, eu insisto, o nó do confronto: é admissível que na tarefa de construir um Estado plurinacional - como foi estabelecido na nova Constituição Política boliviana - um segmento político de especialistas e servidores restabeleçam um lugar de afirmação universal afirmativa - território de expressão estatal por excelência - para decidir sobre questões públicas no lugar de - e sobre a - população? Como devem ser relacionados os múltiplos processos de deliberação política das bases para decidir sobre questões locais - e gerais - que os afetam, com as prerrogativas estatais de "representação" de um "interesse geral" - real ou suposto - que possa garantir legalmente o monopólio estatal da decisão política? Essas são perguntas cujas respostas, mais do que teóricas, são políticas e práticas. São, também, questões cujas respostas são travadas nas lutas locais, regionais e nacionais, e que exibem com clareza o mais notável dos conflitos: o confronto agudo para resolver a prerrogativa de decidir sobre a rota de uma estrada que irá atravessar o Território Indígena e o Parque Isiboro-Sécure (TIPNIS).

Enquanto as cidades que habitam a zona em questão consideram que essa estrada deve beirar os territórios que anos atrás lhes foram reconhecidos com títulos e conectar os pequenos assentamentos ali existentes, os funcionários governamentais e os técnicos da Iniciativa de Integración Regional Sudamericana (IIRSA) consideram que a rota mais conveniente é uma linha reta que atravesse o meio do território. Além do fato de uma ou outra rota apresentarem, também, projetos incompatíveis com o que se entende por "desenvolvimento" (Paz, 2012: 15 e seguintes), o conflito assumiu a forma de uma disputa acirrada sobre como deve ser entendido o "direito à consulta" livre e informada aos povos indígenas, garantido pela Constituição boliviana e também pela Convenção 169 da OIT, quando se trata de obras e projetos que afetam ou alteram seus territórios. E é aqui que está o nó do confronto: nas prerrogativas de decidir sobre o que afeta imediatamente os povos que habitam territórios específicos, e sobre como um Estado plurinacional deveria tomar decisões não "para o bem de ninguém", e principalmente não pelo "bem da nação" - pois é justamente a construção de uma articulação política plurinacional o que está em disputa -, mas atendendo antes à compatibilidade dos diversos interesses locais e respeitando os regulamentos que foram inscritos no próprio texto constitucional plurinacional.

Considerando certo nível abstrato de análise, a aspiração atual dos povos das Tierras Bajas é análoga ao conjunto de demandas e propostas que, em outras circunstâncias, foram levantadas pelos povos das Tierras Altas. Ambos colocam no centro do debate a questão dos termos de inclusão dos povos indígenas - e não apenas deles - em um projeto de articulação plurinacional. 
O confronto, em última instância, é entre diferentes lógicas de produção, defesa e reapropriação do comum com a sua carga de luta concreta contra os argumentos e decisões que são tomados a partir da assim chamada esfera pública, que visa enunciar a partir da representação abstrata de uma totalidade. São, então, duas formas de política, dois modos contrapostos de conceber a política que se confrontam: uma concreta, plural, focada no comum e generalizável, que não constrói modelos abstratos, mas que gera e abre caminhos de reorganização da convivência, que se concentra, também, na defesa e/ou ampliação das condições materiais que garantem a reprodução da vida; e outra forma política focada naquilo que é estatal e que não chega a submeter à crítica - mesmo pretendendo agora ser plurinacional - uma ampla gama de compromissos epistêmicos e ontológicos com a herança da Modernidade capitalista, particularmente a defesa da existência de um lugar totalizante para o que é universal afirmativo - o estatal -, que é o local de enunciação por excelência da acumulação de capital em algumas de suas variantes.

Nesse contexto, os povos do TIPNIS realizaram as VIII e IX Marcha Indígena de las Tierras Bajas em direção à cidade de La Paz em 2011 e 2012, às quais muitos outros contingentes, indígenas e não indígenas, se uniram. O que eu estou afirmando aqui, então, é que além das muitas contradições que se tornaram visíveis, especialmente na IX Marcha, a ação dos povos do TIPNIS pode ser entendida como a implantação de lógicas de defesa do comum, como um compromisso prático com aquilo de que se dispõe e que deve ser produzido sistematicamente a partir de formas específicas de habitar. Nesse sentido, os esforços dos homens e mulheres das Tierras Bajas anunciam e configuram a dificuldade de gerar diferentes formas do político: formas não estadocêntricas do político que, de acordo com o que foi argumentado, são geralmente expressas no feminino.

\section{Conclusão}

Os argumentos aqui apresentados, assim como a breve referência à luta pelo TIPNIS, permitem afirmar que na Bolívia - mas não só ali - existem poderosas lógicas coletivas de produção do comum desdobradas às vezes como sabedoria e disposição coletiva de satisfazer as necessidades e enfrentar os problemas (os sistemas comunitários de água potável, por exemplo) e, em outras ocasiões, como ações belicosas de defesa do que é comum para procurar alcançar direitos coletivos plenos (TIPNIS), como garantia básica da possibilidade de tecer, de baixo para cima, outras articulações satisfatórias com outros povos e com outros interesses. Eu afirmo que essas lógicas de produção, reprodução e defesa do comum, surgidas 
a partir das reiteradas deliberações coletivas em forma de assembleia e que se propõem fins e estabelecem compromissos, permitem distinguir uma forma do político, notável e precisa ainda que multiforme, que é imediatamente contraposta aos interesses da apropriação privada, às lógicas acumulativas abstratas do capital. Além disso, essas lógicas políticas de produção do comum, que se afirmam na vontade coletiva de construir e defender condições materiais satisfatórias para garantir a reprodução material da vida, quase sempre mantêm uma tensa relação com as práticas estatais e com a esfera pública. Sob o olhar das lógicas heterogêneas de produção do comum, o público-estatal não é mais do que a deformação de um suposto comum ampliado que, no entanto, ao esvaziar-se de qualquer conteúdo concreto no processo de abstração [abstractalización] que organiza a sua consagração estatal, permite processos de expropriação múltipla (Navarro, 2012), isto é, de alienação e monopólio da capacidade de decidir - além da espoliação de riqueza material - que são novamente impugnados desde baixo.

Nesses termos, a política estatal que privilegia algum tipo de acumulação de capital, assim como as lógicas governamentais de comando que colapsam a questão política em procedimentos chamados de "tomada de decisões", estabelecem uma tensa ligação com as dinâmicas sociais multiformes e heterogêneas de produção do comum baseadas na garantia de reprodução da vida. A disputa mais visível ocorre, em termos políticos, quando há confronto entre riquíssimas formas deliberativas de produção da decisão política baseadas na circulação da palavra e na produção tendencial de acordo com conjuntos de procedimentos estatais que inibem de forma sistemática a deliberação coletiva - concentrando o monopólio da voz em especialistas - e ao colocarem em figuras "autorizadas" a prerrogativa de decisão sobre assuntos de interesse coletivo.

Para alguns, a disputa para manter aberta a possibilidade coletiva de produção da decisão política e para não concentrar as prerrogativas de decisão sobre assuntos coletivos se desenvolve a partir de propósitos concretos e particulares organizados ao redor da produção e defesa do comum, que por sua vez é a garantia da reprodução da vida humana e não humana. Esta disposição para a deliberação e produção da decisão política não é só uma herança compartilhada como é, basicamente, um ato repetido de (re)criação e atualização de conhecimentos sociais; os argumentos são tecidos como direito comum e sua legitimidade não se baseia apenas na força coletiva, mas em uma poderosa disputa pelos critérios morais que estabelecem termos de inclusão para entidades políticas maiores. Em contraste, segundo a outra posição, ligada ao território institucional do governo, as prerrogativas de decisão se fortalecem com o reforço das práticas de delegação tipicamente modernas, e os argumentos são emitidos 
desde o lugar abstrato e vazio da universalidade estatal supostamente abrangente. Esta é, do meu ponto de vista, a tensão que está atualmente dilacerando a construção de Estados plurinacionais em nosso continente.

Como tem se mostrado na Bolívia, no Equador e atualmente no Peru e na Guatemala, as lógicas de produção do comum, sempre particulares e locais, têm, no entanto, uma poderosa possibilidade de generalização e transbordamento, de articulação política e comunização [comunización]. Elas não são, portanto, localistas nem particularistas, não são míopes nem minúsculas. Elas se assentam, sim, em apoios [acuerpamientos] de homens e mulheres solidamente fundamentados, mas suas possibilidades e horizontes não finalizam no âmbito limitado de seus pequenos interesses. A esse pequeno âmbito restrito e insignificante visa reduzi-las a outra lógica, a lógica política nitidamente masculina do capital e do Estado. No entanto, a política no feminino, as múltiplas dinâmicas de produção e defesa do comum focadas em garantir as condições materiais para a reprodução da vida, são apresentadas mais uma vez na esfera pública em um esforço para serem generalizadas e transbordar o limites em que elas sistematicamente são situadas. É nestas potências, e não na perspicácia racional de ninguém, nem na sempre precária capacidade dos aparatos estatais cercados por gigantescos interesses privados, que há a possibilidade e está a força para se imaginar-produzir ações e horizontes de transformação política e social. Distinguir e reconhecer as características desta política no feminino e, acima de tudo, compreender as lógicas sempre relacionadas e sempre diferentes de produção do comum que são construídas e reconstruídas no nosso continente, é caminhar em direção à auto-emancipação comum.

Puebla (México), abril de 2013.

\section{REFERÊNCIAS BIBLIOGRÁFICAS}

ESCÁRZAGA, F. y R. Gutiérrez (coord.), Movimiento indígena en América Latina: resistencia y proyecto alternativo, vol. II, México DF: Juan Pablos-BUAP-UAM-UACM-GDF, 2006.

FEDERICI, Silvia, Calibán y la bruja. Mujeres, cuerpo y acumulación originaria, Buenos Aires, Tinta Limón, 2011 [también México, Pez en el Árbol, 2013].

GUTIÉRREZ, Raquel, Los ritmos del Pachakuti. Levantamiento y movilización en Bolivia (2000-2005), México DF, ICSyH-BUAP/Bajo Tierra Ediciones, 2009.

GUTIÉRREZ, Raquel, «Los ritmos del Pachakuti. Cómo conocemos las luchas de emancipación y su relación con la política de la autonomía», Desacatos. Revista de Antropología Social, núm. 37, 2011. 
GUTIÉRREZ, R., A. García y L. Tapia, «La forma multitud de la política de las necesidades vitales», en El retorno de la Bolivia plebeya, La Paz, Comuna, 2000.

GUTIÉRREZ, R. y H. Salazar, «El accidentado camino del Buen Vivir: horizontes indígenaoriginario-campesinos en Bolivia durante el gobierno de Evo Morales», Revista ALASRU, núm. 7, 2013.

HEGEL, G. F., Filosofía del derecho, Buenos Aires, Editorial Claridad, 1968.

LINSALATA, Lucía, Cuando manda la Asamblea. Lo comunitario-popular en Bolivia: una aproximación desde los sistemas comunitarios de agua de Cochabamba, Tesis doctoral en Estudios Latinoamericanos, México, UNAM, 2014.

NAVARRO, Mina Lorena, Luchas por lo común. Antagonismo social contra el renovado cercamiento y despojo capitalista de los bienes naturales en México, Tesis doctoral en Sociología, México, ICSyH-BUAP, 2012.

PAZ, Sarela, «La marcha indígena del TIPNIS y su relación con los modelos extractivos de América del Sur» en M. P. Chávez et al., Extractivismo y resistencia indígena en el TIPNIS, La Paz, Autodeterminación, 2012.

RIVERA, María-Milagros, El fraude de la igualdad, Buenos Aires, Librería de Mujeres, 2002.

TAPIA, Luis, «Los pueblos de tierras bajas como minoría plural consistente» en M. P. Chávez et al., La victoria indígena del TIPNIS, La Paz, Autodeterminación, 2012. 